Aletria, Belo Horizonte, v. 29, n. 1, p. 37-51, 2019

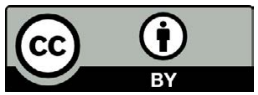

\title{
O duplo pacto representativo: porosidades e enganos do real em Tijuana, de Gabino Rodríguez
}

\section{The Double Representative Pact: Porosities and Tricks of the Real in Tijuana, by Gabino Rodríguez}

\author{
Júlia Morena Costa \\ Universidade Federal da Bahia, Salvador, Bahia / Brasil \\ juliamorenacosta@gmail.com
}

Resumo: Este ensaio objetiva analisar a peça Tijuana, do coletivo "Lagartijas tiradas al sol", baseado no romance colombiano, 6 meses con el salario mínimo, de Andrés Solano. A obra teatral propõe a discussão acerca das vidas possíveis no norte mexicano, a partir da experiência do ator Gabino Rodríguez, convertido durante seis meses em Santiago Ramírez, habitante de Tijuana, sob condições específicas que o afastaram do seu mundo habitual enquanto trabalhava nas maquiladoras mexicanas. A partir da análise dos textos dramático e espetacular, objetiva-se discutir os porosos limites entre o real e o ficcional, através dos efeitos de real provocados nos textos, ao utilizar o princípio da experiência pessoal compartilhada com o leitor/público.

Palavras-chave: dramaturgia; real; política; Tijuana; Andrés Solano; Gabino Rodríguez.

Abstract: This essay aims to analyze Tijuana, a play enacted by the collective "Lagartijas tiradas al sol", based on the Colombian novel, 6 meses con el salario minimo, written by Andres Solano. The play proposes a discussion on possible lives in northern Mexico, based on the experience of actor Gabino Rodríguez, converted for six months in Santiago Ramírez, a resident in Tijuana, under specific conditions that kept him away from his usual world while working in the Mexican maquiladoras. From the analysis of the dramatic and spectacular texts, this paper aims to analyze the porous boundaries between the real and the fictional, through the effects of real provoked in the texts, using the principle of personal experience shared with the reader/audience.

Keywords: dramaturgy; real; politcs; Tijuana; Andrés Solano; Gabino Rodríguez. 
O que significa democracia no México, nos dias atuais, para cerca de 50 milhões de pessoas que vivem com o salário mínimo? O que esperamos da democracia hoje em dia? O que esperamos da política para além da democracia? A economia condiciona a maneira com a qual experimentamos a política e as expectativas que temos?

A partir destas perguntas, está elaborada Tijuana (estreada em 2016), obra dramática escrita, dirigida e encenada por Gabino Rodríguez, que compõe o projeto "Democracia", do coletivo mexicano "Lagartijas tiradas al sol". Para discutir o conceito e a construção de democracia no país, discorrendo sobre os direitos e a dignidade das populações, principalmente as mais marginalizadas, está prevista a criação de 32 espetáculos, um para cada região da república mexicana. A proposta é uma tentativa de construir uma reflexão que entenda as múltiplas experiências de democracia, na qual, mais que expor uma explicação, se requeira uma implicação desde seus diversos pontos. Para isso, são propostas perspectivas diversificadas e atomizadas da questão, que pretendem discutir algumas problemáticas dos processos modernizadores pelos quais o país passou desde a revolução mexicana até os dias atuais.

Em "Tijuana" - uma das 32 partes - a discussão se centra nas condições laborais, a partir da premissa do direito ao salário mínimo como suposta garantia de dignidade social e econômica que pudesse assegurar adequadas condições de habitação, transporte, alimentação, vestuário e demais necessidades básicas de um cidadão trabalhador e sua família. Como anuncia a premissa da obra na voz de Gabino Rodríguez em um dos vídeos projetados durante a peça:

Eu comecei a trabalhar sobre a ideia do salário mínimo. Interessava-me muito considerar qual acordo nós, como sociedade, temos para retribuir o trabalho menos qualificado. O salário mínimo não é uma quantidade que dependa do crescimento do investimento econômico ou da produtividade, é um acordo que a sociedade realiza para determinar um mínimo indispensável com o qual alguém pode viver com dignidade. $\mathrm{E}$ isso era algo que me interessava muito. Tentar viver, tentar compreender, quais eram as implicações de viver com essa quantia. Obviamente, essa quantia, esse preço, é determinado por pessoas que representam outras pessoas e as pessoas que 
determinam esse preço jamais experimentam o que é viver com o salário mínimo. ${ }^{1}$

Este aporte, garantido por lei, será o único ganho de Gabino em sua experiência e relato no norte do México, que centra um sem número de maquiladoras: grandes fábricas, que empregam uma significativa quantidade de mão de obra pouco qualificada que recebe o salário mínimo. Por essa sistemática, o norte mexicano é um lote de sustentação do capitalismo mundial, capaz de gerar uma produção enorme a custos muito baixos, devido, principalmente, à baixa remuneração da numerosa mão de obra. Estima-se que a taxa de desemprego na região esteja próxima a $1 \%$, o que evidencia que essa área responde mais a uma produção e mercado mundial que às inconstâncias de um mercado ou de uma economia interna.

As precárias modernizações realizadas no norte mexicano são propícias para abrigar esse modo de produção explorador e, nesse sentido, o governo é conivente e promovedor dessa condição, juntamente ao mercado mundial. Faz-se importante sinalizar a especial condição do governo mexicano neste processo: desde o fim da revolução mexicana e nos 71 anos ininterruptos em que o PRI (Partido Revolucionário Internacional) se manteve no poder, entre 1929 e 2000 , sempre se prometeu democracia social e melhores condições de vida à sua população, ainda que, a duros golpes, o partido não tenha conseguido frear o aprofundamento dessa situação do seu povo. Nos últimos anos, esta questão foi atualizada quando o PRI voltou à presidência na figura de Enrique Peña Nieto, retomando as implicações políticas e históricas do partido no processo modernizatório e na garantia de direitos dos mexicanos. A tendência latino-americana, e talvez mundial, de abertura máxima das leis estatais às exigências do mercado, que promovem regras trabalhistas flexibilizadas, ocasionando

\footnotetext{
1 "Yo comencé a trabajar sobre la idea del salario mínimo. Me interesaba mucho considerar qué acuerdo tenemos en la sociedad para retribuir al trabajo menos calificado. El salario mínimo no es una cantidad que dependa del crecimiento de la inversión económica o de la productividad, es un acuerdo que realiza la sociedad para determinar un mínimo indispensable con lo que alguien puede vivir con dignidad. Y eso era algo que a mí me interesaba muchísimo. Intentar vivir, intentar comprender, cuáles eran las implicaciones que tiene vivir con esa cantidad. Obviamente esa cantidad, ese precio, es determinado por personas que representan a otras personas y las personas que determinan ese precio jamás experimentan lo que es vivir con el salario mínimo." (RODRIGUEZ. Tijuana, tradução nossa).
} 
condições insalubres de habitação, um salário insuficiente para a garantia da vida mínima, educação precarizada e voltada para a formação de mão de obra barata, são, cada dia mais, a realidade do norte mexicano cuja economia se sustenta com os postos nas maquiladoras. Esse contexto socioeconômico funda cidades e assentamentos habitacionais em volta das fábricas, cuja precariedade e marginalização contam com uma justiça insuficiente e sem penetração nas diversas comunidades que se estabelecem aí, sob um regime de grande violência, nas quais residem grande parte dos seus trabalhadores.

E justamente esse cenário social que acomoda a obra Tijuana, ao propor a reconstrução da experiência de um ator imerso nessas condições ao se disfarçar e passar cinco meses dedicado ao trabalho em uma maquiladora, vivendo dos recursos exclusivos do salário mínimo, sob uma identidade e um nome falsos, Santiago Ramírez. Essa é a premissa da construção de um território em cena que possa compartilhar um sensível social com seu público. ${ }^{2}$ Aproximar o espectador a sentir, a partir de uma experiência real, as questões, angústias, limitações, dores e descobertas de uma experiência como trabalhador não qualificado e mal pago, pautando que essa dor momentânea do ator é cotidiana, constante e rotineira do trabalhador nestas condições em Tijuana.

Gabino Rodríguez se disfarça, aluga um quarto na casa de uma família e ali vai viver por um semestre como mais um entre tantos outros trabalhadores das maquiladoras. No cenário, nos relata cada momento distintivo dessa experiência, suas dúvidas, seu medo de ser descoberto pelos vizinhos e colegas de fábrica, a dor que sente no corpo devido ao trabalho executado e à dificuldade em conciliar seus gastos básicos com o dinheiro que ganha a cada mês. Essa ação cênica de relato, às vezes analítico, às vezes performático, está entrecortada, a cada momento, por vídeos de entrevistas realizadas para a televisão, nas quais conta sobre sua experiência de ator travestido de trabalhador braçal, e de fotografias, vídeos e áudios gravados com seu celular na vizinhança da comunidade na qual vivia, projetados em uma tela que ocupa posição de destaque no palco. Também são apresentados trechos de seus diários, produzidos durante a experiência, que contém os relatos ainda frescos das vivências neste longo período de experimento. Estes documentos, irrompem nas construções cênicas, contrastando com a estética da encenação presente, e trazem uma

${ }^{2}$ Cf. RANCIÈRE. A partilha do sensivel. 
alta dose de realidade ao espaço representativo. Além destes, durante toda a obra, o ator compartilha conosco, espectadores, seus processos criativos, o que ajuda a estabelecer com seu interlocutor o caráter de cumplicidade neste "pacto de realidade". O ator também nos garante que não pretende interpretar um operário ou falar por ele sobre suas angústias e expectativas, o que diminuiria sua complexidade humana. Sua proposta, pelo contrário, é a de interpretar a si mesmo na sua própria experiência de um ator imerso na vida de um trabalhador de fábrica. É uma experiência, portanto, não redutora do outro, mas sim legitimada por usar sua própria voz e vivência e falar de e por si mesmo, de sua autorepresentação, inclusive, no sentido da representatividade, o que lhe confere, assim, ainda mais aparência e legitimidade na sensação de ser testemunha da realidade:

Decidi viver seis meses em Tijuana ganhando o salário mínimo.

Não sei qual será minha casa, se terei amigos, se um dia dormirei com uma mulher.

Minha única certeza é um cargo em uma maquiladora que consegui através de um conhecido.

Viver/sobreviver com um salário que segundo a lei deve "satisfazer as necessidades normais de um chefe de família".

A partir de hoje eu não sou eu, sou outro: Santiago Ramírez.

Tenho outro nome, outro passado, outra história, outra vida.

Na carteira trago um calendário para marcar os 176 dias em que viverei como o que não sou, nos quais atuarei o que para outros é a vida. 176 dias nos quais buscarei realizar as fantasias que tenho todo o tempo, nas quais imagino a mim mesmo vivendo uma vida que não é a minha.

Assim são minhas fantasias, assim são as realidades de todo mundo. ${ }^{3}$

\footnotetext{
3 "He decidido vivir seis meses en Tijuana ganando el salario mínimo. / No sé cuál será mi casa, si tendré amigos, si un día me acostaré con una mujer. / Mi única certeza es un puesto en una maquiladora que conseguí a través de un conocido. / Vivir/sobrevivir con un sueldo que según la ley debe "satisfacer las necesidades normales de un jefe de familia”. / A partir de hoy yo no soy yo, soy otro: Santiago Ramírez. / Tengo otro nombre, otro pasado, otra historia, otra vida. / En la cartera traigo un calendario para tachar los 176 días en que viviré como lo que no soy, en los que actuaré lo que para
} 
No entanto, o que não se explicita durante toda a montagem do espetáculo nem em nenhum outro material que acompanha a apresentação é que este texto, e esta experiência, não são originárias da vida do ator, diretor e dramaturgo Gabino Rodríguez - ainda que sejam do personagem Gabino Rodríguez - mas sim fazem parte do texto Seis meses con un salario mínimo, de Andrés Felipe Solano, autor colombiano, que narra sua suposta experiência de, a partir de um encargo jornalístico, se disfarçar de trabalhador de uma fábrica do norte da Colômbia, e, após um período de vivência ali, relatar suas condições laborais e de vida. O romance, posteriormente publicado com o título Salario mínimo: vivir sin nada está narrado em forma de um diário e contém o texto que agora ocupa a boca do personagem de Gabino Rodríguez, ainda que essa informação, repetimos, não seja entregue ao seu público em nenhum momento durante a apresentação da peça.

Essa tradução do romance ao teatro, com intensa apropriação e mascaramento da sua adaptação, provoca um choque nas fronteiras tipicamente esperadas entre o real e o ficcional nesta criação cênica. Não se trata simplesmente da tendência das últimas décadas do teatro contemporâneo de trazer elementos do real ao espaço ficcional, com pouco ou nenhum tratamento estético de modo a manter sua potência de realidade, que invade o espaço representativo e sinaliza os limites deste último.

Esta obra, como contraproposta, toma elementos da ficção - o romance - e os traslada a registros não ficcionais - documentos, fotos, entrevistas - com uso de grande elaboração estética para alcançar este efeito para, por fim, apresentá-lo no contexto tradicional da representação: o teatro. Ou seja, constrói-se o real e seus efeitos a partir do ficcional, para, por fim, apresentá-los no espaço da representação, friccionando os possíveis limites ou pactos pré-estabelecidos entre as esferas documentais e ficcionais.

Silvia Fernandes nos recorda que a tendência de uso do real nas propostas dramatúrgicas contemporâneas não se faz a partir de um simples objetivo estético, mas também, e principalmente, se configura como uma proposta de ética relacional. Ou seja, o desejo pelo real, tanto dos espectadores como dos atores/dramaturgos, parece afirmar que "a

otros es la vida. 176 días en los que buscaré realizar las ensoñaciones que tengo todo el tiempo, en donde me imagino a mí mismo viviendo una vida que no es la mía. / Así son mis ensoñaciones, así son en realidad las de todo el mundo." (RODRIGUEZ. Tijuana, tradução nossa). 
representação da realidade se fez inoperante e devesse ceder lugar à irrupção da própria realidade em cena", ${ }_{4}$ como uma "necessidade de abertura do teatro à alteridade, ao mundo e à história, em detrimento do fechamento da representação". ${ }^{5}$ Fernandes afirma ainda que

a face mais evidente dessa crise [de representação na sociedade contemporânea], é o deslocamento dos mecanismos teatrais, representativos e políticos, para uma postura diferencial dos artistas, que revela um desejo de ação frente ao outro e a intenção de recuperar a possibilidade social em termos menores. ${ }^{6}$

Abordar as questões laborais que hoje tomam grande parte da agenda política ${ }^{7}$ da América Latina e suas implicações diretas na dignidade humana, ganha uma especial projeção de afetações no teatro ao usar de uma possibilidade de testemunho da realidade que reafirma, ainda que seja de conhecimento do sentido comum, as dores dos trabalhadores a partir de uma experiência pessoal compartilhada. Usa-se do efeito de real na aproximação de um tema de grande relevância social e com grande apelo empático junto ao seu público, ainda que rompa com o suposto espelho experiencial, por estar baseado não na vivência do ator, mas sim no romance colombiano. Tal fato explicita que esse real, ou efeito de real, potencializado, não necessita ser um dado absorvido de uma experiência da realidade, mas sim, um pacto.

Gabino Rodríguez afirma que:

A ficção não é uma substância, é um marco de leitura. É um acordo entre alguém que apresenta algo e alguém que o testemunha, sobre a natureza do que é apresentado. Essa natureza manifesta que o que vai ser apresentado deve ser

\footnotetext{
${ }^{4}$ FERNANDES. Experiências do real no teatro, p. 5

${ }^{5}$ FERNANDES. Experiencias do real no teatro, p. 4.

${ }^{6}$ FERNANDES. Experiências do real no teatro, p. 7-8.

${ }^{7}$ No âmbito brasileiro, essa questão vem se acirrando nos últimos anos, com a crescente precarização das condições de trabalho e queda da remuneração e tende a se acentuar com a nova lei trabalhista recentemente aprovada no congresso nacional. Como dado alarmante, em 2017 foi divulgado que os trabalhadores brasileiros e mexicanos têm remuneração inferior aos de fábricas chinesas, conhecidas pela exploração da mão de obra local. Cf. TRABALHADOR brasileiro já ganha menos do que um chinês, aponta estudo. Folha de S. Paulo. 26 fev. 2017.
} 
lido como uma invenção, como resultado da criatividade de alguém. O drama não é ficção, a ilusão não é ficção, a ficção é um acordo, um pacto, um contrato.

A ficção é algo que acontece na realidade, mas que não é a realidade, é uma interrupção da realidade. ${ }^{8}$

Desde nossa perspectiva nesse ensaio, afirmamos: assim também pode ser entendida a realidade no teatro. $O$ real cênico não é sempre uma substância, um elemento físico ou uma presença, mas sim um marco de leitura, um pacto. O real é um acordo sobre a natureza do que será apresentado, que pode ser provocado por uma série de elementos que reafirmarão esse lugar de entendimento e de trato. O terreno ficcional é um jogo que se dá em um espaço-tempo determinado, que propõe elaborar estruturas inteligíveis e dentro de uma proposta compartilhada. Por fim, a arte não tem contas para prestar quanto à "verdade" do que diz, porque, no seu princípio, não está feita de enunciados, e sim de ficções, ou seja, de coordenação de atos. ${ }^{9}$ A partir deste ponto, discuto com Silvia Fernandes: o que move o interesse pelo real no teatro na contemporaneidade, na minha perspectiva, não é o desejo pelo real em si mesmo, mas pela forma com que o real pode afetar os presentes. $\mathrm{O}$ que necessitamos é criar uma arena de comprometimento com seus participantes, uma ética relacional intensa, que nos permita estabelecer espaços de coparticipação dos sentidos instaurados em cena e atuantes no mundo. A crise no teatro não é somente representativa, é relacional, o que por fim, nos exige buscar outras formas de aproximação à alteridade, ao mundo, à história. $\mathrm{O}$ público, talvez esgotado pelo fastio de tanta ficção se vê com o desejo de se reconectar com a realidade, talvez porque grande parte de nossa vida se converteu em uma grande ficção - desde o âmbito pessoal ${ }^{10}$ ao dos grandes acontecimentos

8 "La ficción no es una sustancia, es un marco de lectura. Es un acuerdo entre alguien que presenta algo y alguien que lo atestigua, sobre la naturaleza que tiene lo que se presenta. Esa naturaleza manifiesta que lo que se va a presentar debe ser leído como una invención, como resultado de la creatividad de alguien. El drama no es ficción, la ilusión no es ficción, la ficción es un acuerdo, un pacto, un contrato. La ficción es algo que sucede en la realidad, pero que no es la realidad, es una interrupción de la realidad.” (RODRIGUEZ. ¿Cuántos ladrones se necesitan para inaugurar una cueva?, p. 18, tradução nossa).

${ }^{9}$ RANCIÈRE. A partilha do sensivel, p.53-54.

${ }^{10}$ Muito se discute hoje sobre o papel de novas plataformas de comunicação, como a internet, por exemplo, nas relações interpessoais e as criações de perfis e informações que 
políticos dos últimos anos, como a grande ocorrência da chamada pósverdade nas últimas eleições dos EUA e do Brasil, por exemplo. A ficção já está tão presente na construção de nossos imaginários e a verdade já tão questionada nos registros de suposta realidade, como nos telejornais, por exemplo, que a comoção se faz infértil nestes espaços. Seria a busca pela verdade no espaço teatral um desejo de apreender um discurso diferente do já tão propagado terreno da ficção ou ainda uma perda da credibilidade de espaços geralmente dados aos discursos que se pretendem documentais? Patrice Pavis defende que "Para o indivíduo, essa busca do real é também, e acima de tudo, um modo de encontrar e reforçar a expectativa e a atenção sobre si e no outro, para não se tornar uma máquina, para manter o elo social". ${ }^{11} \mathrm{E}$, por estas e outras razões, somos envolvidos por um desejo por espaços reais de afetação, que, em geral, recaem sobre os acontecimentos/ momentos de realidade insurgentes nos espaços representativos. Esse desejo de pacto do real pode levar o espectador, inclusive, a negar que está frente a um palco teatral, espaço por natureza do representativo, e aceitar um pacto de realidade, ou seja, desejar um pacto de realidade. Essa experiência, que pode ser ficcional ou não, forjada ou não (forjada no duplo sentido que a palavra nos permite, de falseada ou de moldada), se convence o espectador, pode conferir um discurso inquestionável de entendimento e aceitação do que está sendo representado. ${ }^{12}$

Nesse sentido, em Tijuana presenciamos um grande trabalho de lapidação estética para alcançar os efeitos de real, (pois o real é também uma estética que se alcança). $\mathrm{O}$ uso de fotografias feitas em um telefone celular, com imagens de baixa qualidade, enquadramentos inconsistentes, tremores de uma mão amadora no uso da câmera, gravações escondidas, etc. Efeitos que são rapidamente explicados por nosso personagem para

não, necessariamente, são fieis a uma realidade verificável no mundo físico. Ademais, o recorte, a edição e a reorganização das informações pessoais, voluntariamente compartilhadas, podem ser entendidas como a construção de uma (auto)ficção usada para sustentar relações e interações entre as pessoas. Claudio Valdés Curi, do Coletivo mexicano Ciertos Habitantes, por exemplo, considera que qualquer discurso, ainda que retirado da realidade, que é organizado para um determinado fim, se torna ficcional.

${ }^{11}$ PAVIS. Uma redefinição do teatro político, p.174.

${ }^{12}$ Um grande efeito desse pacto de realidade é o possível entendimento de que o público está diante de uma "pessoa" e não de um personagem fictício, de uma testemunha de um ato ou momento e que, portanto, de um saber ou experiência inquestionável em sua veracidade e/ou de legitimidade de lugar de fala. 
ganhar verossimilhança. Como diz o personagem em vídeo constante na peça, que simula uma entrevista para a televisão local sobre a vivência no norte mexicano e o processo de criação da peça e dos materiais documentais:

Decidi fazer um projeto com isso, mas não queria tomar fotografias pela comunidade, não queria ser percebido como um artista, e sim, totalmente o contrário. Então, comecei a gravar com uma câmera e uma gravadora de som muito pequenas e gravava escondido. O som era obviamente mais fácil, mas para a câmera, normalmente, tinha que colocá-la na manga e enquanto ia caminhando tratava de gravar algo. Tentava fazê-lo da maneira mais discreta possível. ${ }^{13}$

As projeções e objetos de cena (entrevista pessoal, com microfone típico de redes televisivas; um diário com desenhos e manuscrito à caneta azul e de folhas deterioradas pelo uso; um tíquete da fábrica, com o número de roupas guardadas por Gabino em um dia determinado) artefatos, cuidadosamente elaborados para manter estreita identidade com documentos do real, imprimem o selo de veracidade da ação. É importante ressaltar que há um grande trabalho de decodificação das características de ditos artefatos (objetos, vídeos, fotografias, sons e documentos) no que lhes concederia aparência de pertencentes ao mundo/vivência exterior ao teatro para o posterior preparo dos mesmos, de modo a alcançar a estética de real buscada. A construção do real nessas cenas contrasta com a prática anteriormente enunciada de não intervenção estética nos objetos trazidos à cena para proporcionarem a experiência de um artefato ou presença do real no palco cênico, que faz parte de propostas declaradas de muitas obras atuais. Em Tijuana, como afirmado, o caminho é oposto: de intensa intervenção estética para a decodificação e criação, de forma a estabelecer o "pacto de real". Esse cuidadoso preparo dos materiais proporciona uma aproximação do espectador com a presença desses supostos documentos e fazendo-o participar de uma partilha

13 "Decidí hacer un proyecto con esto pero no quería tomar fotografías por la colonia, no quería ser percibido como un artista, sino todo lo contrario. Entonces empecé a grabar con una cámara y una grabadora de sonido muy pequeñas y grababa de incógnito. El sonido era obviamente más fácil, pero con la cámara normalmente la metía en la manga y mientras iba caminando trataba de grabar algo. Lo trataba de hacer de la manera más discreta posible." (RODRIGUEZ. Tijuana, tradução nossa). 
testemunhal, promovendo uma credibilidade da vivência dentro de um espaço do representativo, de forma a torná-lo crível. Acreditamos que a sensação de presenciar o real instaurado e irrompido em cena, pode diminuir os efeitos de distanciamento do espectador possibilitados pela decodificação da ficção, criando uma zona de maior implicação pessoal e entrega afetiva. É uma estratégia de comoção e convencimento pela força do real (ou pela impressão do real).

FIGURA 1 - Tijuana (Cena com cenário e trecho do diário na tela)

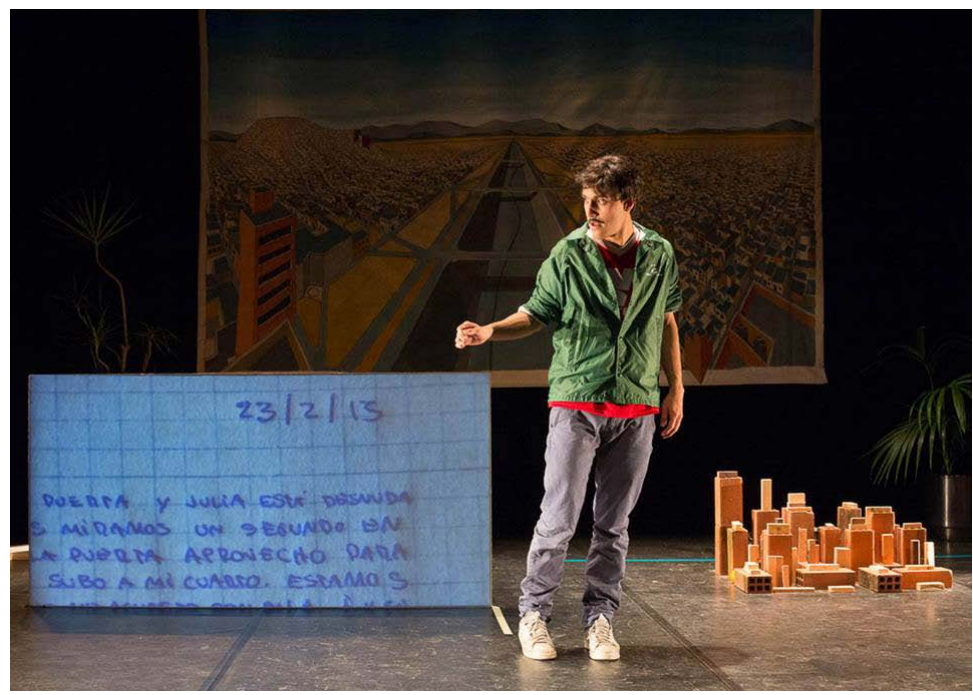

Fonte: arquivo pessoal de Gabino Rodriguez ${ }^{14}$

Faz-se importante também destacar o grande contraste estético proposto pela peça entre o fazer do ator em cena, com suas representações e escolhas de cenário e de objetos, declaradamente simbólicos ou não documentais, com o que é apresentado como documentos virtualizados pela imagem digital na tela que ocupa posição central no palco (entre fotos, anotações, entrevistas, vídeos, sons). O cenário de fundo se trata de um desenho estilizado da comunidade em que pretensamente viveu, e não de uma foto que pudesse propor uma documentação de suposta fidelidade com o espaço mencionado. Assim como as marcações espaciais referidas à casa em que habitava se faz com desenhos de fita crepe no

\footnotetext{
${ }^{14}$ Agradeço a Gabino Rodríguez a cessão das fotos do espetáculo Tijuana para esta publicação.
} 
chão e as construções vizinhas são representadas por tijolos e garrafas empilhadas (ver figura abaixo). Parece-nos importante aqui sinalizar o caráter supostamente assumido pela fotografia e vídeo como mais fieis a uma realidade representada por seus meios que as pinturas ou desenhos. Essas presenças virtualizadas no palco se complementam e se diferenciam do cenário desenhado, trazendo o caráter de testemunho de uma vivência/ estância em um lugar. Como reafirmado por Karl Erik Schøllhammer ao se referir à fotografia: "Desse modo, esses fragmentos podem ainda guardar uma riqueza semântica que qualifica simbolicamente o ambiente, mas sua função mais importante é produzir o efeito do 'isso foi', central na definição do 'efeito do real' de Roland Barthes." 15 O contraste entre as proposições estéticas de um e de outro âmbito - a cena teatral presente e os documentos virtualizados pela imagem da tela - intensifica ainda mais o lugar, supostamente separado, ocupado pelo real e pelo representacional em cena, propondo uma dicotomia que os potencializa.

$$
\begin{gathered}
\text { FIGURA } 2 \text { - Tijuana - (Detalhe do cenário com marcas dos cômodos } \\
\text { da casa no palco) }
\end{gathered}
$$

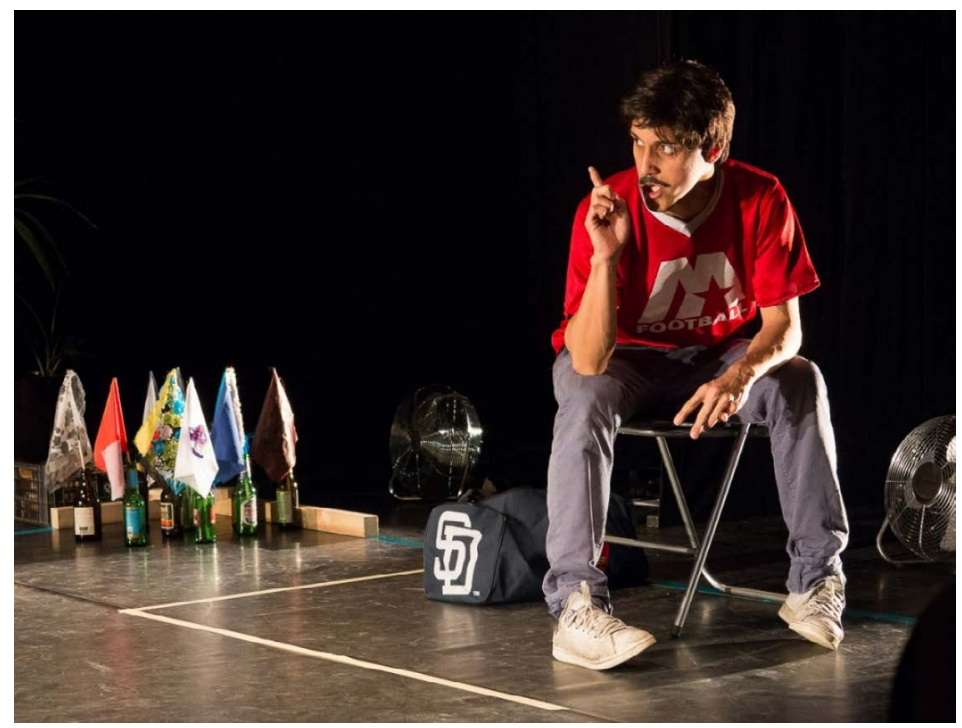

Fonte: arquivo pessoal de Gabino Rodriguez

${ }^{15}$ SCHØLLHAMMER. Realismo afetivo: evocar realismo além da representação, p.167. 
Enfatizamos que o regime representacional se especifica por uma separação da ideia de ficção e da mentira, pois isso "autonomiza as formas das artes no que diz respeito à economia das ocupações comuns e à contra economia dos simulacros, própria ao regime ético das imagens". ${ }^{16}$ Rancière nos propõe uma diluição das fronteiras clássicas ou marcadas entre o real e o ficcional, afirmando que sua nítida separação representa, também, a impossibilidade de uma racionalidade histórica, ${ }^{17}$ uma vez que esta está marcada pelos dois regimes de maneira complexa. O filósofo ainda afirma: "a revolução estética redistribui o jogo, fazendo solidárias as indefinições entre a razão dos fatos e a razão das ficções." A soberania estética da arte seria "[...] uma indistinção tendencial entre a razão das ordenações descritivas e narrativas da ficção e as ordenações da descrição e interpretação dos fenômenos do mundo histórico e social". ${ }^{18}$ Quer dizer, o real necessita ser ficcionalizado para ser pensado, ${ }^{19}$ passar pelo reordenamento narrativo humano, estetizado e inserido no jogo decifrável, acordado e compartilhado entre as partes. Patrice Pavis também o afirma:

A ficção, a artificialidade do jogo, a intensidade, são necessárias para a descoberta de elementos do real e para a sua elucidação. O trabalho artístico e formal (mas não formalista) é uma etapa indispensável quando as formas e a dramaturgia esforçam-se para revelar conteúdos sóciopolíticos ou psicológicos. ${ }^{20}$

E que:

o único critério de uma representação clara e justa da sociedade é saber se os espectadores sentemse representados enquanto grupo que corresponde a essa representação, se o teatro dá conta de sua situação e se consegue esboçar uma solução para ela com os procedimentos da ficção. ${ }^{21}$

\footnotetext{
${ }^{16}$ RANCIÈRE. A partilha do sensivel, p. 53

${ }^{17}$ RANCIÈRE. A partilha do sensivel, p. 54.

${ }^{18}$ RANCIÈRE. A partilha do sensivel, p. 55.

${ }^{19}$ RANCIÈRE. A partilha do sensivel, p. 58.

${ }^{20}$ PAVIS. Uma redefinição do teatro político, p. 174.

${ }^{21}$ PAVIS. Uma redefinição do teatro político, p. 174.
} 
Por isso, e por fim, defendemos que, em lugar de ativar uma experiência vivida pelo ator, o uso de um romance que pretende ser uma reprodução de uma experiência do real como base para a obra teatral, Tijuana potencializa o lugar do ficcional e do real como discursos poderosos para criar espaços de comprometimento social e estético. Tijuana traz à cena a problematização do valor do real enquanto um acordo com seu espectador, mais do que como um apego inegociável com a verdade, tensionando o lugar representativo como tal. O cruzamento entre os dois regimes - o real e o ficcional - os aproxima como arenas estéticas relacionais entre espectador e obra, ambas baseadas em pactos que podem, dentro do espaço da representação, tocar no que lhe escapa e lhe ultrapassa.

\section{Referências}

FERNANDES, Silvia. Experiências do real no teatro. Sala Preta. São Paulo: Universidade de São Paulo. v.13, n.2, p. 3-13. 15 dez. 2013. DOI: https://doi.org/10.11606/issn.2238-3867.v13i2p3-13

PAVIS, Patrice. GAMA, Mônica. Uma redefinição do teatro político. Sala preta. São Paulo: Universidade de São Paulo. v. 13, n. 2, p.171-175. 15 dez. 2013. DOI: https://doi.org/10.11606/issn.2238-3867.v13i2p171-175

RANCIÈRE, Jacques. A partilha do sensível: estética e política. Tradução de Mônica Costa Netto. São Paulo: EXO; Editora 34, 2005.

RODRIGUEZ, Gabino. ¿Cuántos ladrones se necesitan para inaugurar una cueva? Amsterdam: DAS theater. Academy of theater and dance. Amsterdam University of the arts, 2017. Disponível em: $<$ http://lagartijastiradasalsol.com/wp-content/uploads/2017/10/ CuantosLadrones_ESP_ok1.pdf>.Acesso em: 12 fev. 2019.

RODRIGUEZ, Gabino. Tijuana. Folheto da peça, 2016.

SCHØLLAMMER, Karl Erik. Realismo afetivo: evocar realismo além da representação. In: SCHØLLAMMER Karl Erik. Cena do crime: violência e realismo no Brasil contemporâneo. 1. ed. Rio de Janeiro: José Olympio, 2013.

SOLANO, Andrés. 6 meses con el salario mínimo. SoHo, Bogotá, n. 91, 14 nov. 2007. Disponível em: <http://www.soho.co/historias/ 
Aletria, Belo Horizonte, v. 29, n. 1, p. 37-51, 2019

articulo/salario-minimo-legal-vigente-cronica-de-como-sobrevivir-conun-salario-minimo/887>. Acesso em: 10 out. 2016.

SOLANO, Andrés. Salario mínimo: vivir sin nada. Bogotá: Tusquets Editores, 2015.

TRABALHADOR brasileiro já ganha menos do que um chinês, aponta estudo. Folha de S. Paulo, São Paulo, 26 fev. 2017. Disponível em: $<$ https://www1.folha.uol.com.br/mercado/2017/02/1862186-trabalhadorbrasileiro-ja-ganha-menos-do-que-um-chines-aponta-estudo.shtml $>$. Acesso em: 31 jan. 2019.

Recebido em: 17 de setembro de 2018.

Aprovado em: 22 de janeiro de 2019. 